\title{
La ficción del milagro económico español a la luz de la crisis financiera
}

\author{
Rafael IBÁÑEZ ROJO \\ Universidad Autónoma de Madrid \\ rafael.ibanez@uam.es \\ Pablo LÓPEZ CALLE \\ Universidad Complutense de Madrid \\ plopezca@cps.ucm.es
}

Recibido: 04-01-2012

Aceptado: 22-05-2012

\section{RESUMEN}

El presente artículo se sitúa en el contexto del cambio de fase en el desarrollo del capitalismo, un cambio marcado por un modelo de crecimiento basado en el uso extensivo de la mano de obra y la extracción de plusvalías absolutas. El deforme crecimiento de la economía española será analizado como un síntoma de las nuevas formas de acumulación y rentabilización del capital dominante en los últimos años. Desde ese punto de partida, el objetivo es en primer lugar, analizar los efectos de la financiarización económica sobre las estrategias de las corporaciones industriales, considerando siempre que esa influencia es dependiente de los contextos institucionales y de la estructura social de los territorios sobre los que la financiarización opera. Mediante el estudio de dos sectores de actividad concretos (el automóvil y la fabricación de software), intentamos explorar los rasgos principales de las transformaciones organizativas que van a dar lugar a los nuevos modelos de producción, así como evaluar algunos de sus efectos sobre las condiciones de producción y de reproducción de la estructura social: cómo, por una parte, ello ha supuesto una recomposición del poder de las clases dominantes a escala global mediante la formación de grandes oligopolios internacionales; y por otra, una profunda reordenación de las formas de consumo de la fuerza de trabajo.

Palabras clave: financiarización; organización del trabajo; gobierno corporativo; automóvil; fabricación de software.

\section{The fiction of the Spanish economic miracle in the light of the financial crisis}

\begin{abstract}
This article starts by drawing the turning point in the development of capitalism, describing a change marked by a new growth model based on the extensive use of labor and the extraction of absolute gains. The deformed growth of the Spanish economy will be analyzed as a symptom of the new forms of capital accumulation and profitability dominant in recent years. From this starting point, the goal is first to analyze the effects of economic financialization on the strategies and corporate governance of industrial corporations, always considering that this influence is dependent on the institutional and social structure of the territories on which financialization operates. Through the study of two specific sectors (automotive and software manufacturing), we try to explore the main features of the organizational changes that will lead to new patterns of production and to evaluate some of its effects on the conditions of production and reproduction of the social structure: how, on the one hand, this has meant a restructuring of the power of the global ruling classes through the formation of large international oligopolies and, secondly, a profound reorganization in the forms of workforce consumption.
\end{abstract}


Keywords: financialization; work organization; corporate governance; automotive industry; software manufacturing.

\begin{abstract}
"Y cada nuevo empréstito brindaba a la aristocracia financiera una nueva ocasión de estafar a un Estado mantenido artificialmente al borde de la bancarrota; éste no tenía más remedio que contratar con los banqueros en las condiciones más desfavorables.[...] En general, la inestabilidad del crédito del Estado y la posesión de los secretos de éste daban a los banqueros y a sus asociados en las Cámaras y en el trono la posibilidad de provocar oscilaciones extraordinarias y súbitas en la cotización de los valores del Estado, cuyo resultado tenía que ser siempre, necesariamente, la ruina de una masa de pequeños capitalistas y el enriquecimiento fabulosamente rápido de los grandes especuladores"

(K. Marx, La lucha de clases en Francia)
\end{abstract}

\title{
REFERENCIA NORMALIZADA
}

Ibáñez Rojo, R. y López Calle, P. (2012). La ficción del milagro económico español a la luz de la crisis financiera. Cuadernos de Relaciones Laborales Vol. 30, núm. 2, p. 379-407.

SUMARIO: Introducción. 1. El desarrollo del proceso de acumulación de capital en occidente y la superación del modelo Fordista-Keynesiano. 2. Financiarización de la economía y gobierno empresarial. 3. Nuevas estrategias productivas. 3.1. Nuevos modelos de fabricación de bienes de consumo de gamas medias y bajas: el automóvil como paradigma. 3.2 El desarrollo del subdesarrollo en nuevas tecnologías de la información. 4. Conclusiones. 5. Referencias bibliográficas.

\section{Introducción}

El objetivo central de este artículo es analizar el fenómeno de la financiarización de la economía en los países occidentales en las últimas décadas como resultado de un proceso de transformación del modelo productivo fordista-keynesiano, que en países de la semiperiferia europea como el nuestro, ha mutado hacia formas de obtención de rentabilidad del capital basadas en la intensificación del trabajo y la extracción de plusvalor absoluto. De tal forma que este proceso de financiarización de la economía había coadyuvado por largo tiempo a mantener la ficción del llamado milagro económico español de entre siglos, mientras se ponía en marcha un modelo productivo basado en la esquilmación de los recursos disponibles y en la continuidad de la dinámica de deslocalización del capital productivo a otras regiones del planeta.

Pero ello implica realizar, en primer lugar, una breve lectura crítica de los presupuestos neoliberales que están detrás de las reformas económicas y laborales que se plantearon como solución a la crisis de desempleo de los años ochenta en nuestro país. Planteamientos que se vuelven a presentar hoy como solución a la crisis actual, y que han servido más bien de coartada ideológica para llevar a cabo la transformación del modelo mencionado: bajo estos supuestos, fenómenos como el desempleo, la sobreproducción, la inflación, el sobreendeudamiento o las burbujas inmobiliarias se explican necesariamente a partir de la existencia de interferencias sociales o políticas en el libre funcionamiento la oferta y la demanda de empleo, de bienes o de servicios, que habrían provocado una desviación en su justo precio, dando lugar, 
entre otras cosas, a la interrupción del flujo natural del capital por sus distintas formas y limitando con ello el constante incremento de la riqueza social a partir del uso eficiente de los recursos técnicos y humanos disponibles. Desajustes que, por su propia definición, y según el tautológico modo de proceder de la economía vulgar ${ }^{l}$, señalan como solución el restablecimiento de las condiciones de libre mercado ( sinónimo conceptual de 'ajuste' ${ }^{2}$ ) mediante políticas de liberalización, también llamadas precisamente políticas de ajuste.

Pero lo cierto es que, según trataremos de demostrar en este artículo, esa precaria situación económica y social en la que se ha sumergido un volumen creciente del asalariado en esta región del mundo es parte del propio desarrollo del proceso global de acumulación ampliada del capital y no producto de su interrupción o mal funcionamiento. Señala más bien, como apuntábamos, la transición desde una fase

${ }^{1}$ La "economía vulgar" es el calificativo que aplica Marx en distintas partes de su excelsa obra a los postulados económicos previos a la economía política clásica, representada por Smith, Say, Mill o Ricardo: aquélla que trata de investigar la "concatenación interna" (y no sólo aparente, como haría la citada economía vulgar) "del régimen burgués de producción". No obstante, los autores incluidos por Marx en la economía política clásica, al no ser capaces de identificar la diferencia entre el valor de la fuerza de trabajo y el valor del trabajo diferencia que explica el origen del plusvalor, y por tanto, la ampliación de esta diferencia como la lógica de funcionamiento del sistema capitalista de producción-, comparten con la economía vulgar el análisis de las crisis económicas y los "modos de proceder" para resolverlas. Para estas perspectivas las crisis económicas resultan de la desutilidad marginal de los factores productivos mencionados -por ejemplo cuando existe desempleo involuntario-, pero como el libre mercado es la institución que maximiza la utilidad de los factores productivos, de ello se deduce que no existe un auténtico libre mercado. (Marx, 1959: Libro I, 57).

Por estas razones, dicho de paso, la tesis central de este artículo, como afirmamos en el párrafo siguiente, sostiene que el momento económico actual, presentado por la economía vulgar como un episodio de crisis o interrupción del buen funcionamiento del mercado, puede que sea más bien un fenómeno funcional y necesario al proceso global de acumulación capitalista.

${ }^{2}$ En la literatura de la Economía política clásica encontramos esta asimilación presentada de distintas formas (la mano invisible de Adam Smith, la Ley de Say, etc.), he aquí, una de las más acabadas: "“Cuando los precios de las mercancías bajan en un mercado debido a una oferta abundante, a una disminución de la demanda o a un alza del valor del dinero, un industrial acumula naturalmente una extraordinaria cantidad de artículos manufacturados, y no está dispuesto a venderlos a precios depreciados. Para hacer frente a sus pagos ordinarios, a los cuales atendía con la venta de sus mercancías, trata ahora de tomar el dinero en préstamo, y a menudo se ve obligado a pagar por él un interés elevado. Pero esto sólo es temporal, pues o bien las esperanzas del industrial estaban bien fundadas, o bien descubre que la demanda ha disminuido de modo permanente y no se resiste más al curso de las cosas: los precios bajan y el dinero y el interés recobran su valor real», vale decir: "se ajustan". (Ricardo, 1994: 60). 
de dicho proceso de acumulación, la que protagonizó el modelo de producción Fordista-Keynesiano durante gran parte del siglo XX, hacia un nuevo modelo de extracción de plusvalor con bajos índices de bienestar social. De tal manera que el período comprendido entre los primeros síntomas de agotamiento del modelo anterior en los años setenta y el momento actual se interpreta aquí como un período de transición hacia otras formas de vivir y de trabajar que, a priori $-\mathrm{y}$ siempre en función del desarrollo de los conflictos y resistencias sociales-, van a permitir la reproducción del proceso de acumulación ampliada de capital.

En el primer epígrafe del artículo analizamos algunos de los efectos de la caída de las tasas de ganancia en occidente en el último tercio del siglo pasado, que vinculamos a los propios efectos del desarrollo del modelo Fordista-Keynesiano mencionado. En primer lugar, la contradicción interna entre, por una parte, la tendencia decreciente de la tasa de ganancia a medida que aumenta el capital constante, y por otra, la necesidad de que éste crezca ininterrumpidamente para compensar, mediante el incremento de la masa de ganancia, la citada reducción en la tasa. Contradicción que tendrá como consecuencia el acelerado proceso de financiarización de la economía. Y, en segundo lugar, tratamos de analizar cómo la progresiva caída del valor real de la fuerza de trabajo por debajo del valor formal o legalmente establecido, a consecuencia del constante incremento de la productividad del trabajo y el abaratamiento de los medios de consumo encarecerá relativamente los costes laborales de las empresas radicadas en los países centrales. Lo que servirá de coartada legitimatoria para flexibilizar el mercado de trabajo y liberalizar la economía - facilitando los flujos de trabajadores y mercancías-, así como para la deslocalización del capital productivo.

Sentadas estas bases, nuestra reflexión tratará de hacer visibles, en primer término, y ocupando el grueso del segundo epígrafe, los efectos de la financiarización económica sobre las estrategias de las corporaciones industriales, considerando siempre que esa influencia es dependiente de los contextos institucionales y de la estructura social de los territorios sobre los que la financiarización opera. Y finalmente, en el tercer epígrafe del artículo, mediante el estudio de dos sectores de actividad concretos (el automóvil y la fabricación de software), intentamos explorar los rasgos principales de las transformaciones organizativas que van a dar lugar a los nuevos modelos de producción mencionados, así como evaluar algunos de sus efectos sobre las condiciones de producción y de reproducción del sistema social: cómo, por una parte, ello ha supuesto una recomposición del poder de las clases dominantes a escala global mediante la formación de grandes oligopolios internacionales; y por otra, una profunda reordenación de la estructura y las formas de consumo de la fuerza de trabajo orientada a la intensificación del trabajo (sintetizada en las continuas transferencias del capital a países emergentes del sudeste asiático, y en las transformaciones en el ámbito del trabajo y del empleo de las economías occidentales). 


\section{El desarrollo del proceso de acumulación de capital en occidente y la supe- ración del modelo Fordista-Keynesiano}

El modelo de producción denominado Fordista-Keynesiano, predominante en el bloque capitalista occidental durante gran parte del siglo XX, se había caracterizado por formas de explotación del trabajo basadas en el llamado plusvalor relativo, es decir, en el incremento de la productividad del trabajo mediante la innovación tecnológica, la producción estandarizada y el consumo de masas.

Hasta los años 1980 las estrategias empresariales respondieron a la consolidación de un «estatuto salarial» ${ }^{3}$ que permitía desvincular los salarios y las condiciones de trabajo - estipulados mediante normas de aplicación universal— del trabajo individual entregado en el puesto de trabajo, mediante la institucionalización de la negociación colectiva; mientras, por otra parte, la estabilidad en el empleo, el seguro de desempleo y los salarios altos permitían mantener los niveles de demanda coherentes con el mencionado incremento de la productividad. Por otra parte, este modelo se había sostenido también sobre la base de una desigual transferencia de valor internacional, del sur al norte, entre un centro capitalista que consumía el 80\% de los bienes producidos en todo el mundo, mientras la periferia, produciendo el $80 \%$ de dichos bienes - fundamentalmente materias primas- sólo consumía el $20 \%$. El centro se reservaba la transformación y la fabricación del producto para sus propias áreas, dejando tan sólo a los países pobres las tareas de extracción de los productos naturales (Palloix, 1980: 222).

La crisis económica en el centro capitalista en los años 1970 se evidencia en una fuerte caída de la inversión que se justifica por los altos costes laborales y la excesiva rigidez del mercado de trabajo. Sin embargo, es más bien el resultado de la caída del valor real de la fuerza de trabajo por debajo de los salarios legal y formalmente establecidos - y por debajo del precio de la tecnología sustituida por ella $-{ }^{4}$, lo que

\footnotetext{
${ }^{3}$ Entendemos por «estatuto salarial» el conjunto de relaciones de fuerza y mecanismos institucionales que fijan los derechos y deberes de la relación salarial típica en un momento dado, es decir, aquella relación salarial respecto a la cual las demás formas de contratación y consumo de fuerza de trabajo son consideradas desviaciones; y que, por tanto, funciona como un atractor en la regulación de los mercados de trabajo. Una de las mejores reconstrucciones, realizada desde el punto de vista histórico, de la construcción social del estatuto salarial sigue siendo la obra de Robert Castel (1997).

${ }^{4}$ Ello se produce, en primer lugar, por el progresivo abaratamiento de los medios de subsistencia (motivado por el incremento de la productividad) y en segundo lugar, por la propia desvalorización del trabajo (efecto de la reducción del número relativo de ocupados por el incremento de la composición de capital que permite incrementar la productividad). Consideramos aquí que si, en términos generales, podemos suponer que la opción por un modelo productivo basado en la obtención de rentabilidad mediante el incremento de plusvalor relativo, esto es, mediante el incremento de la productividad-, presupone la inversión
} 
lleva a un cambio de modelo productivo orientado ahora a la intensificación del trabajo y la extracción de plusvalor absoluto. Lo cual, al mismo tiempo, habría hecho disfuncional aquella manera universalista de fijar las condiciones de trabajo (separación formal entre salarios y cantidad de trabajo individual entregada).

La lucha social y política que subyace a la salida de la crisis de los años ochenta tendrá que invertir radicalmente esta tendencia alumbrando un nuevo modelo de capitalismo a partir de la segunda mitad de los años 1980. Como recoge el Gráfico 1, desde mediados de los años 1970, la recuperación de la inversión se ha mantenido sobre una caída permanente del peso de la masa salarial en el PIB (aunque no del número de ocupados), síntoma de un nuevo contexto para el tipo de relación salarial que se irá haciendo predominante en las empresas de las economías desarrolladas.

en tecnología en un sentido amplio (máquinas, técnicas organizativas, formación, etc...), esta decisión está determinada «por la diferencia que existe entre el valor de la misma y el valor de la fuerza de trabajo que reemplaza». Y como «el salario real del obrero ora cae por debajo del valor de su fuerza de trabajo, ora supera dicho valor, la diferencia entre el precio de la maquinaria y el precio de la fuerza de trabajo que debe sustituir puede variar considerablemente (precisamente, como acabamos de ver, debido a las variaciones en el valor de los medios de subsistencia en función del incremento o el decremento de la productividad del trabajo), por más que la diferencia entre la cantidad de trabajo necesaria para la producción de la máquina y la cantidad total del trabajo sustituido por ella se mantenga invariable» (Marx, 1959, Libro I, 425-444). 
GRÁFICO 1. Evolución de la formación bruta de capital fijo (precios constantes año 2000) y porcentaje de los salarios en el PIB. EU15, 1960-1992

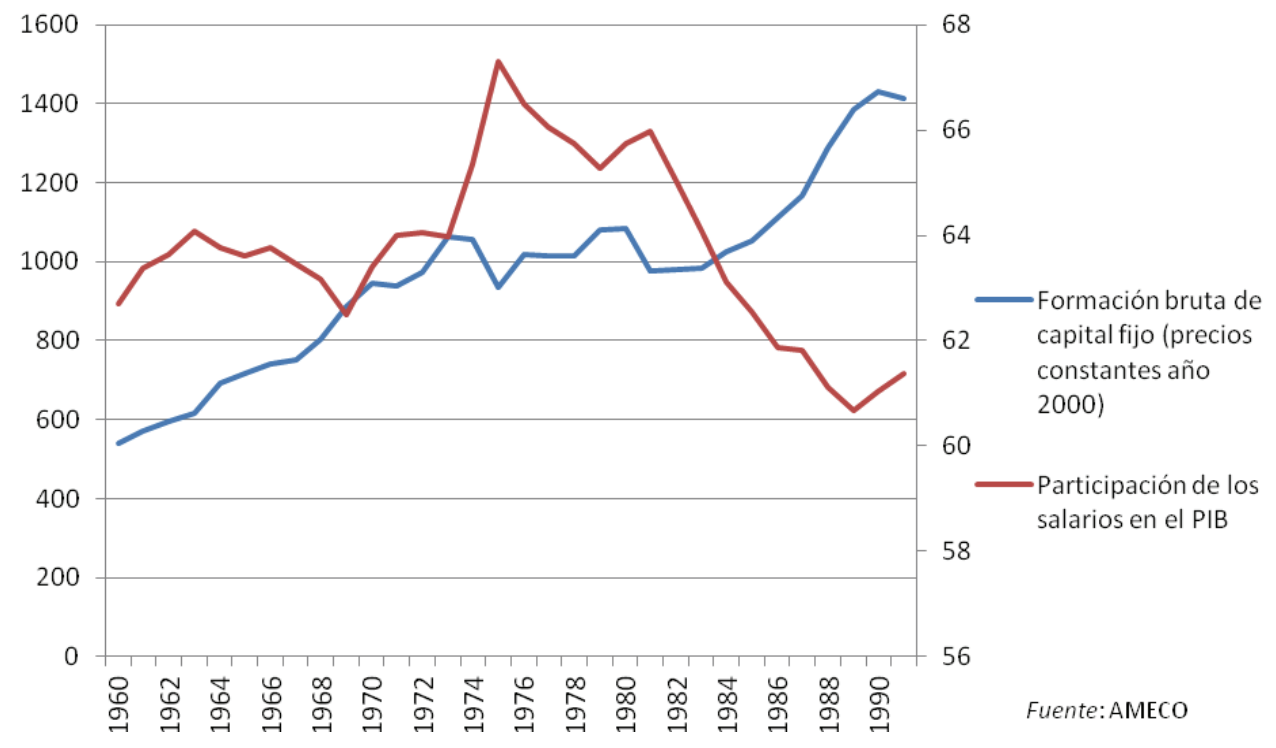

Los inversores habrían procedido a "disciplinar" el intervencionismo estatal mediante: el ahorro (la desinversión y el consiguiente efecto del desempleo); la deslocalización productiva a otros países de más bajos costes laborales; y seguramente también mediante la extensión de la economía oculta e informal, tal y como constatamos en los años 1980 en España. De forma que en esos años se produce un giro teórico o ideológico en la ortodoxia económica que traslada las prioridades políticas hacia la primacía absoluta de la restauración del beneficio empresarial cortoplacista. La resolución del conflicto de clases expresado de múltiples formas en los años 1970 (aumento de la conflictividad laboral, reducciones en la productividad, crisis internacional, etc.), condujo - no sin violencia - a un conjunto de políticas orientadas a reconducir la distribución de la riqueza hacia el excedente empresarial.

Así, el ajuste del salario legal (normas y mínimos del estatuto salarial) al valor real de la fuerza de trabajo se realizará mediante la desregulación del mercado de trabajo y la liberalización de los mercados a nivel internacional, aunque la coartada legitimatoria de estas reformas será, por una parte, la necesidad de solucionar la crisis de desempleo en los países ricos, y por otra, permitir el desarrollo económico de países no industrializados. Con ello se dará paso, en las últimas décadas del siglo XX, a un modelo de desarrollo mundial orientado de manera general al uso extensivo del trabajo como forma de incrementar la rentabilidad del capital a partir 
de la extracción del llamado plusvalor absoluto ${ }^{5}$. El efecto estructural será una reducción ininterrumpida del coste laboral unitario medio en las economías desarrolladas, reducción que esconde una reducción muy superior entre los estratos de trabajadores con menor cualificación o situados en los lugares con menor capacidad política de negociación.

Gráfico 2. Evolución del coste real unitario (compensación por persona empleada respecto al PIB nominal ). UE15 y varios países, 1960-2012

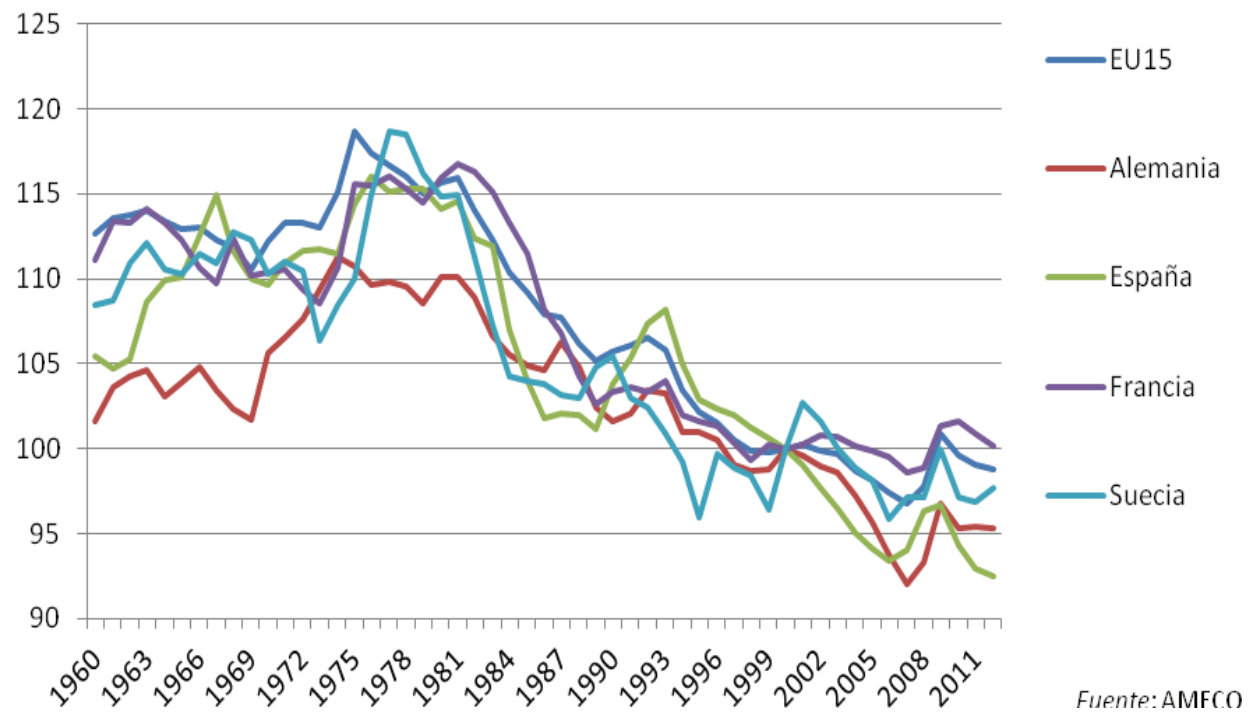

Esta tendencia hacia un crecimiento extensivo del consumo de la fuerza de trabajo, en definitiva, a la recuperación de los beneficios sin ganancias en productividad, supone, por ejemplo, casos como el modelo de crecimiento español que será

${ }^{5}$ La visualización más evidente del cambio hacia un modelo basado en el consumo extensivo de la fuerza de trabajo es el crecimiento de la mano de obra disponible como recurso para el diseño de los procesos de trabajo a escala global que realizan las grandes corporaciones. Considerando el peso de las exportaciones en las economías nacionales, el Fondo Monetario Internacional calcula que entre 1980 y 2005 la oferta de mano de obra mundial se habría cuadruplicado - fundamentalmente por la apertura de la Europa del Este y las economías asiáticas- (FMI 2007: 179). Casi todo este nuevo crecimiento se concentra en la oferta de mano de obra de baja cualificación y ello es lo que permite comprender el debilitamiento del poder político real experimentado por los trabajadores asalariados de escasa cualificación en las economías desarrolladas 
capaz de crear más de 7 millones de empleos durante los años de mayor crecimiento económico (entre 1995 y 2008) mientras descendía el salario real y la productividad crecía de forma muy moderada.

De este modo, el decrecimiento de las tasas de ganancia en las condiciones anteriormente apuntadas de progresiva disminución real del valor de la fuerza de trabajo, mientras se mantenían formalmente costes laborales relativamente más elevados, conllevará, en lo inmediato, la necesidad de compensar dicho decrecimiento a través del recurso al capital financiero y de formas de extracción de plusvalor absoluto basadas en la intensificación del trabajo, que se acompañará de distintas transformaciones en la organización de las empresas a nivel global y en las estrategias organizativas de la producción.

\section{Financiarización de la economía y gobierno empresarial}

La mencionada caída de las tasas de ganancia, consecuencia de las contradicciones propias del desarrollo del modelo fordista-keynesiano, tal y como hemos apuntado, va a ser compensada, en parte, y coyunturalmente, mediante el recurso al capital financiero ${ }^{6}$. Ahora bien, desde el punto de vista del contexto organizacional, ello va a tener distintas consecuencias sobre los nuevos modelos empresariales y productivos, que van a pasar a estar supeditados a la lógica de su captación ${ }^{7}$.

A) En primer lugar, se ha convertido ya en lugar común del análisis organizacional la orientación estratégica del gobierno corporativo hacia el aumento del valor de las acciones (shareholder value), con el objetivo de contentar las exigencias de los grandes inversores (Froud el al., 2006). Sin embargo, esta dinámica sólo añade inestabilidad e incertidumbre en el conjunto del sistema económico. En este sentido, desde el punto de vista del gobierno corporativo, la información «imperfecta» sobre el valor de los activos que manejan los intermediarios financieros y las agencias de calificación de riesgos los convierte en un criterio muy débil para la gestión estratégica de las corporaciones (Aglietta 2008: 410 y ss.). Ello se debe especialmente a las dificultades para computar el valor de los principales recursos intangibles, y tomarlos en consideración sin asumir grandes riesgos para evaluar el poder de las

\footnotetext{
${ }^{6}$ Otra de las causas de esta intensa financiarización será la contradicción interna entre las distintas fases de la rotación del capital: pues la necesaria ampliación continuada del capital fijo aumenta el tiempo durante el cuál una parte del capital se encuentra en su fase de capital productivo, detrayendo, en el ínterin, capital disponible para realizar el plusvalor que se va creando, más rápidamente, en forma de mercancías (sobreproducción). Marx aporta otras teorías de la crisis a lo largo de su obra central, aunque realmente sean, en última instancia, distintas manifestaciones o desarrollos de la fórmula general del capital. Aquí sólo hemos hecho referencia a dos de ellas (Marx, 1959, Libro II: 136-308 y Libro III: 213-263).

${ }^{7}$ Hemos seguido y adaptado aquí los argumentos manejados por Robert Boyer (2000; 2011).
} 
corporaciones en el largo plazo. Todos los recursos ligados al conocimiento y la información, los más relevantes a medio plazo para las grandes corporaciones en la actualidad, tienen una medición limitada o nula en las estructuras contables (conocimiento contenido en software y bases de datos, conocimiento derivado de innovación y desarrollo y actividades creativas, conocimiento inserto en los recursos humanos y organizativos), por lo que las evaluaciones realizadas por las agencias de calificación contienen un mayor nivel de incertidumbre. Los datos recogidos por Froud et al. (2006: 77) muestran que en las dos décadas que van entre 1983 y 2002 , el $75 \%$ de las rentas anuales de capital provenían del aumento del precio de las acciones y tan sólo el 25\% de los ingresos y beneficios distribuidos como dividendos. Estos autores vienen a sostener que el aumento del precio de las acciones funciona de una manera relativamente independiente, afectado por variables externas que no son la gestión e iniciativa, creatividad, etc. de los altos ejecutivos a los que se remunera con sueldos desorbitados. Ello ha llevado a cuestionarse la forma tradicional de entender la separación de las lógicas de acción entre gestores y propietarios de las grandes organizaciones, debido al nuevo tipo de alianza surgido de los acuerdos de sobresueldos, los contratos blindados y la «reelitización» de las estructuras empresariales (Plihon y Mouhoud, 2009).

De este modo, la sobrevalorización de las cotizaciones habría sido el resultado de la singular adaptación de las organizaciones al nuevo contexto social y económico. Las dificultades para rentabilizar inversiones productivas en las economías desarrolladas, debido al estancamiento estructural de la demanda (resultado de la reducción de los salarios reales y el desmantelamiento del Estado de Bienestar), convirtieron la liberalización de las transacciones financieras en un proceso necesario para encontrar nuevas vías de rentabilización del capital. Ahora bien, un capital financiero «independiente» (por ejemplo, inversores instituciones que posean participaciones en el accionariado de una corporación) no sólo implica un cambio en la distribución del poder en el interior de muchas empresas, sino que convierten el «riesgo financiero» en el criterio básico de gestión corporativa. Fusiones, «adelgazamientos» y deslocalizaciones se convierten así en procesos fundamentales para generar estructuras organizativas mínimas (o muy centradas en el control oligopolístico de un segmento del mercado) capaces de someterse a la alta rentabilidad a corto plazo que exige un mercado financiero desregulado y de escala mundial. La gestión flexible de la mano de obra es desde esta perspectiva una condición más de la minimización del riesgo financiero. Las estrategias reorganizativas se estandarizan, perdiendo importancia su impacto concreto y localmente considerado - que requeriría de un conocimiento directo y cercano de cada realidad productiva-, ganándolo la ortodoxia y la publicidad de los ajustes, directamente proporcional a su dureza ${ }^{8}$. Esta relación entre financiarización y estructura organizativa de las

${ }^{8}$ Un botón entre muchos: "UNILEVER anuncia 20.000 despidos y el cierre de 50 plantas en cuatro años. El grupo sube un 4\% en Bolsa" en El país, 03/08/2007. 
corporaciones ha sido analizada ya desde muy diferentes perspectivas pero casi siempre con lógicas de fondo coherentes con lo que Lazonick y O'Sullivan (2000) llaman el cambio desde la estrategia de «retener y reinvertir» hacia la estrategia de «minimizar y distribuir».

$B$ ) Una segunda característica del nuevo contexto socioeconómico es el papel protagonista que han adquirido los inversores institucionales en la orientación de las estrategias de rentabilidad de muchas corporaciones. Con un poder derivado en muchos casos de la gestión privada de los seguros sociales, desde principios de los años 2000 el peso cuantitativo de los inversores institucionales ha sido enorme en economías como la estadounidense. Crotty (2003) calcula que a comienzos del siglo XXI ya eran responsables de las tres cuartas partes de todo el volumen de intercambio de acciones en EE.UU. Si bien las relaciones pueden ser indirectas, la literatura sobre los inversores institucionales señala cómo los mercados financieros hegemonizados por ellos sobrevaloran la rentabilidad a corto plazo, desincentivando de forma sistemática a las corporaciones que se orienten hacia estrategias de fuertes inversiones y rentabilidad de largo plazo (Davis y Steil 2000; Aglietta, Khanniche y Rigot 2010). La dispersión de las inversiones y la exigencia de máxima liquidez (Álvarez y Medialdea, 2010: 181-182) aumenta el poder para hacer y deshacer posiciones, sometiendo a un tipo de presión nuevo a la gestión corporativa.

En definitiva, esta presión se traduce en la primacía absoluta de la necesidad de sostener la rentabilidad a corto plazo, es decir, de mantener un elevado volumen de dividendos en busca de una cotización siempre creciente. Una dinámica que, de nuevo, se puede convertir en un mecanismo para detraer posibles recursos de la inversión productiva, pues empuja a un crecimiento del endeudamiento y de los costes de capital para garantizar el pago de los dividendos (Orhangazi 2008b: 870). De esta forma, mientras nuevos gestores con rentas ligadas a la cotización priman «estrategias de rentabilidad según volumen de cotización», esta reorientación de la política corporativa tiene, al menos en un sentido, un efecto perverso sobre la desregulación de las condiciones de trabajo y sobre los límites que el contexto económico actual impone a la negociación colectiva. Como señala Orhangazi cuando el trabajador se enfrenta a una dirección corporativa que carece de intereses a largo plazo, en muchos casos la presión de los representantes de los trabajadores difícilmente podrá incorporar elementos sustantivos para su futuro en el proceso de negociación, como nuevas líneas de producto; dotaciones tecnológicas; cursos de formación, etc. Ya que quienes ostentan la propiedad de la empresa no tienen interés real en estas cuestiones que sólo afectan al medio y largo plazo de la política corporativa. El poder financiero se convierte de esta forma en agente directo de desregulación de los mercados de trabajo, intensificando y reproduciendo el proceso que se iniciara en los años 1980: «Desde la perspectiva del capital, la ventaja de los nuevos inversores que adquieren una compañía es que se encuentran en una mejor posición para romper los contratos tanto explícitos como implícitos con los trabajadores y los proveedores, contratos que probablemente los anteriores gestores mantendrían. El reciente auge de los fondos de inversión ha provocado resultados 
similares a la ola de adquisiciones y fusiones de los años $1980[\ldots] \gg$ (Orhangazi, 2008a: 104).

C) La competitividad interempresarial se ha desplazado, por tanto, al mercado financiero (cómo conseguir medios de financiación). Son los mercados financieros quienes asignan entre actividades con tasas de ganancia similares, de modo que la competencia se desplaza de los productos a los propios mercados financieros (Boyer, 2008).

Por ejemplo, los rápidos cambios en la cotización bursátil durante los años 1990 escondían unas fortísimas expectativas de rentabilización, e hicieron que el aumento del peso de los activos financieros de las corporaciones se disparara desde mediados de los años 1990, algo que no es fácilmente interpretable en términos del comportamiento a corto y medio plazo por parte de las grandes corporaciones. De hecho, el resultado de esta lucha por obtener ingresos a través del aumento del valor de las acciones tuvo como resultado que entre 1995 y 2000 (antes del crack de las empresas tecnológicas) la capitalización bursátil en la bolsa de Nueva York pasara del 95.5\% al $152.7 \%$, mientras en Londres pasaba del $121.7 \%$ al $184.3 \%{ }^{9}$. Este proceso, que Álvarez y Luengo (2010) tratan de medir a través de la «tasa de financiarización» de la economía, refleja una reorientación sistemática de la búsqueda de ingresos hacia los mercados financieros en lugar de hacia las inversiones productivas, incluso entre las corporaciones no financieras. Así, por ejemplo, la Contabilidad Nacional de España recoge cómo en los años previos a la actual crisis las adquisiciones de activos financieros por parte de las sociedades no financieras pasó del $13,9 \%$ del PIB en 2003 al 26,2\% en 2006.

Por tanto, ocupa ahora un lugar secundario la competitividad sobre el producto o servicio, pues sus ventajas comparativas se hayan subordinadas a los criterios de valorización a corto plazo impuestos por el mercado financiero. Esto obviamente desplaza los centros de poder y de toma de decisiones en muchas corporaciones y determina los límites para estrategias productivas concretas.

Así, es la presión financiera la que provoca la necesidad de flexibilidad y se refleja en nuevas formas de contratación. La imputación de riesgos por las agencias de calificación está directamente relacionada con la capacidad de adaptación inmediata de la organización, lo cual afecta a la posibilidad de manejar de forma «libre» el coste salarial como variable de ajuste.

D) Estos cambios tienen lugar de forma paralela a la propia internacionalización de la financiación de las inversiones. Es la promesa, la expectativa, de una expansión financiera y productiva global la que alimenta un crecimiento «ficticio» de los valores de cotización. Pero la primera condición de posibilidad para la burbuja financiera creada desde la segunda mitad de los años 1990 fue la internacionalización del capital. Pues aunque tendemos a considerar al capital como apátrida, lo cierto es que a mediados de los años 90, para los países desarrollados, la propiedad

\footnotetext{
${ }^{9}$ Los datos pueden consultarse en www.world.exchanges.org.
} 
del stock de capital era básicamente autárquico. En 1989 los inversores nacionales poseían el 94\% del stock en EE.UU., el mismo porcentaje en el caso de Japón y un 82\% en el caso de Gran Bretaña (Froud et al., 2006: 85). Esta situación comenzó a cambiar radicalmente en la segunda mitad de los años 1990. Los movimientos internacionales de capital se disparan a partir de entonces, y con ellos la presión por crear expectativas para aumentar el valor en bolsa y mantener la distribución de dividendos. Desde este punto de vista, el proceso de internacionalización de los movimientos de capital debe ser leído como un proceso político, una cesión de soberanía estatal impuesto por las grandes corporaciones que podrán utilizar nuevas formas de presión para reorganizar los procesos de trabajo - y las condiciones de los trabajadores - en los distintos contextos del espacio productivo global.

En el modelo productivo anterior la gran corporación dotaba de una autonomía considerable a sus distintas sedes nacionales, dada la autonomía relativa de las estructuras institucionales y de las demandas nacionales. Esta autonomía suponía centros propios de investigación y desarrollo en cada país y, sobre todo, permitía diversidad de estrategias y diversidad de adaptaciones institucionales. Es decir, las grandes corporaciones tendían a extender a escala global su actividad productiva pero impulsando, de forma relativa, la descentralización. Y esa descentralización se apoyaba también en la autonomía financiera de las sedes nacionales de las grandes corporaciones.

Pero en la actualidad, con la presión financiera que introduce la movilidad internacional del capital, si bien la gran corporación sigue planificando la actividad productiva a escala global, lo hace a partir de una centralización y concentración del poder cada vez mayor. Ahora los distintos elementos nacionales forman piezas con grados de autonomía cada vez menores. Puesto que ya no están destinados fundamentalmente a alimentar un mercado interno con recursos financieros propios, sino a formar parte especializada de la oferta y la estrategia financiera en el mercado mundial. La financiarización del capital industrial es también un efecto directo de estas transformaciones, pues la concentración del capital en grandes corporaciones multinacionales permite, por una parte, controlar los precios en un contexto altamente competitivo en costes de producción, y por otra mantener los salarios bajos.

El creciente volumen de inversiones internacionales, al margen de la capacidad de desestabilización financiera y la aparición de crisis periódicas que ha provocado, genera una mayor interdependencia entre las estrategias organizativas de las grandes empresas y los ritmos a corto plazo de la economía global. Sin embargo, la competitividad internacional y la presión que introduce la desregulación financiera no ha implicado obviamente que se haya reducido la importancia de las políticas desarrolladas tanto a nivel estatal como inter-estatal. Precisamente, el concepto de modelo productivo colocaría en el nivel de mayor determinación estructural el modo de inserción de la economía nacional en el mercado global. El margen de elección que desde los gobiernos existe para orientar dicha inserción es probablemente - por estrecho que sea el margen - la decisión política fundamental.

E) Al mismo tiempo, la influencia de los activos financieros en la demanda final de los consumidores se ha vuelto determinante en los ciclos de actividad económica. 
Una reorientación de la estructura de los ingresos (y las expectativas de ingreso) ligadas a la propiedad y los beneficios derivados de ella ha desarrollado la tendencia a que un segmento de los asalariados - de cierta cualificación y entre las grandes corporaciones - tenga acceso a los beneficios financieros, bien a través de inversiones directas o acuerdos de empresa o, más habitualmente, a través de la intermediación de los fondos de pensiones ${ }^{10}$. En definitiva se trata de la generalización del pago según rendimiento a los gestores de la «revalorización» (Geed 2009: 560). De ahí que, como hemos señalado, las perspectivas de ganancia en los mercados financieros tengan una influencia directa en la decisión de ahorrar o gastar y por tanto en la demanda agregada del sistema económico.

En este mismo sentido, durante las últimas décadas ha tenido lugar un alto grado de endeudamiento de las economías domésticas ${ }^{11}$, clave para mantener artificialmente los niveles de demanda en los países del viejo occidente, al menos coyunturalmente hasta que va creciendo la capacidad de consumo del proletariado en las economías emergentes y se va desplazando el eje del comercio internacional hacia el pacífico. Además, y en lo que atañe a la estructura de las organizaciones, éstas se verán afectadas también por la nueva centralidad que la propiedad (mueble e inmueble) y su valorización ha ido cobrando en las sociedades más desarrolladas. Si la seguridad y los servicios públicos derivados de la relación salarial fueron la base de la expansión de la posguerra, puede considerarse que los años 1980 comenzaron a impulsar otro tipo de estímulos muy diferentes para la demanda agregada. Los períodos de crecimiento económico de los últimos años han podido ir acompañados de periodos de estancamiento o incluso retroceso de los salarios reales ${ }^{12}$. Ello ha sido posible gracias a lo que algunos autores han llamado el keynesianismo de precio de activos, es decir, gracias al efecto positivo sobre la demanda que habría creado el aumento del valor de los activos financieros. Así pues, sólo un modelo social reconstruido sobre la propiedad en lugar de sobre el estatuto y los derechos salariales haría posible las estrategias de individualización y de dispersión salarial que caracterizarán a las organizaciones empresariales. Pues sólo este nuevo modelo de desarrollo hará posible el crecimiento de la demanda sin aumentar los salarios y sin aumentar el gasto público.

${ }^{10}$ Algunos datos, basados en una muestra de empresas europeas, sobre la participación de los trabajadores en las acciones de sus empresas pueden consultarse en la página de la "European Federation Employee Share Ownership" (http://www.efesonline.org)

${ }^{11}$ Según la Encuesta Financiera de las Familias del Banco de España la deuda familiar en sólo seis años pasó del ya de por sí alto índice de endeudamiento del $79 \%$ de la renta disponible en 2002, a nada menos que $128 \%$ en 2008.

${ }^{12}$ Esto es lo que trata de mostrar Robert Brenner para el conjunto de la economía mundial (Brenner 2009) y lo que ha analizado hace años José Manuel Naredo junto con otros autores (Naredo 1998; Echeverría, Carpintero y Naredo 1999; Naredo, Carpintero y Marcos 2007). 
F) Por último, la relación entre los estados y la economía también se ha modificado de formas significativas. Por un lado, ha tenido lugar un aumento de la presión sobre el control del gasto debido a la sensibilidad hacia los tipos de interés reales y la dependencia gubernamental respecto a los inversores y sus expectativas de riesgo financiero. Por otra parte, el Estado sólo puede contar con un aumento muy leve de los ingresos debido al escaso crecimiento y la capacidad creciente de evitar las cargas fiscales por los activos inmobiliarios (lo que tiende a trasladar la presión fiscal sobre los salarios y la propiedad inmobiliaria).

Como se ha señalado desde hace años, desde el punto de vista estatal el resultado ha sido una pérdida de autonomía en la gestión política del contexto económico. La internacionalización de la demanda y de los recursos financieros ha ido reduciendo la autonomía de las economías nacionales y ha impulsado el volumen de las inversiones internacionales de corto plazo, pues a medida que el poder estatal se ha ido limitando ha crecido la autonomía de los movimientos financieros. La presión de los capitales acumulados por las economías desarrolladas — sin espacios y actividades propias de revalorización suficientes - contribuyó a la ausencia de regulación internacional y a la incapacidad del FMI para controlar el cambio hacia un sistema financiero movido por los mercados (Aglietta 2002), cuyas consecuencias sólo hemos comenzado a vislumbrar en la última gran crisis económica mundial que se iniciara en 2008. Desde otro punto de vista, la debilidad estatal es favorecida por los agentes financieros, dado que las dificultades de financiación de los sistemas públicos ha permitido el crecimiento de un ámbito de revalorización financiera a través de los sistemas privados de cobertura de riesgos sociales y garantía de rentas.

En conclusión, los nuevos «magos» de la gestión corporativa son aquellos que garantizan un aumento constante de la cotización, en definitiva, magos en la gestión de expectativas. El efecto de esta tendencia fue disparar la importancia de las rentas financieras en el conjunto de las economías desarrolladas - incluso entre las empresas no financieras - y convertir a los mercados financieros en un espacio cuyos niveles de rentabilidad contribuye a absorber recursos que pudieran ser invertidos en actividades productivas ${ }^{13}$. Pero dichos mercados son el órgano de representación de los nuevos grupos sociales dominantes a escala global, y es su presión política la que frena las acciones destinadas a regular las transacciones financieras. En este sentido, parece evidente la existencia de una relación global en el medio plazo entre financiarización económica y crecimiento de la desigualdad en la distribución social de las rentas (Zalewski y Whalen 2010). El proceso general obedece, en las economías desarrolladas, a un debilitamiento de las rentas salariales y un crecimiento del peso de las rentas de capital y de la riqueza patrimonial que ha transformado profundamente las relaciones de fuerza entre las clases sociales en las últimas décadas. Debido a que el peso de los salarios en la demanda global ha sido menos determi-

${ }^{13}$ Un análisis detallado al respecto para la economía estadounidense puede encontrarse en Orhangazi (2008b). 
nante (por un lado porque la demanda que más crece es la de las economías en desarrollo y por otro como resultado de los incrementos de valor en el capital mobiliario e inmobiliario), la capacidad de negociación de los grupos sociales dependientes exclusivamente del salario se ha ido debilitando.

\section{Nuevas estrategias productivas}

Como acabamos de descubrir, además del recurso al capital financiero, y en parte debido a su creciente hegemonía en el funcionamiento del ciclo de producción y reproducción del capital, dada la coyuntural caída de las tasas de ganancia empresarial y la mencionada dependencia bursátil de las corporaciones empresariales, el modelo productivo estará acompañado de un cambio hacia la intensificación del trabajo, es decir, a estrategias de rentabilidad cortoplacistas basadas en la extracción de plusvalor absoluto: incrementando las cargas de trabajo, disminuyendo los salarios, e incorporando nuevos efectivos con peores condiciones de trabajo al sistema productivo. Para lo cual serán necesarias las conocidas reformas en la regulación del mercado de trabajo, que abaratarán y flexibilizarán formalmente el empleo, y políticas empresariales de reorganización de los procesos de trabajo, cuyas pautas generales analizaremos brevemente a continuación, tomando como ejemplos dos sectores significativos del sistema productivo español.

En primer lugar, la búsqueda de altos niveles de rentabilidad bursátil de los capitales más fuertes para captar financiación da lugar, en primera instancia, y a modo de espiral que se retroalimenta, a una intensa concentración oligopolística del capital productivo internacional en las fases cercanas a la venta del producto final. La captación de capitales servirá a su vez para ampliar los oligopolios que permitan incrementar su cotización accionarial, etc. Ahora bien esa concentración de capitales en la cúspide de los procesos productivos será seguida de una no menos intensa microempresarialización en sus fases iniciales. Dicho de otra manera, las grandes multinacionales copan los mercados a costa de quedarse sólo con las fases del proceso productivo de mayor valor añadido, cerca de los centros de consumo, donde encontramos "Buenas" Formas de Organización del Trabajo (toyotismo, distritos industriales, etc.) caracterizadas por altos niveles de productividad, alta tecnología, altos salarios, y altas cualificaciones, pero que se sostienen sobre la base de sucesivos niveles de subcontratación donde vamos descubriendo tareas de menos valor añadido, más intensivas en trabajo vivo, con trabajadores menos cualificados y con peores condiciones de trabajo ${ }^{14}$.

${ }^{14}$ Por ejemplo, aunque los trabajadores de la industria del metal empleados en países de la OCDE sólo representan el $42 \%$ de todos los trabajadores del metal del mundo, producen alrededor del $87 \%$ del valor añadido mundial. En cambio, los 40 millones de empleados $(58 \%)$ en países no pertenecientes a la OCDE crean tan sólo el $13 \%$ del valor añadido. Se 
En segundo lugar, y en consonancia con este fenómeno de jerarquización vertical de las empresas en función de su lugar en el proceso de producción, la competencia en torno a los márgenes en los precios que ofrecen las diferencias regionales de costes laborales, sobre todo en las empresas que realmente fabrican los bienes y servicios, ha llevado a la aplicación de sistemas organizativos del tipo de la fabricación ligera o la fabricación justo a tiempo, mediante los cuales, las empresas consiguen, por una parte, abaratar costes laborales mediante la fragmentación de los procesos y al externalización de actividades, y por otra, reducir los costes derivados de los cambios en los mercados, producto precisamente de la elevada competencia, que se trasladan a los eslabones más débiles en las cadenas de subcontratación. Siendo las pequeñas empresas e incluso los trabajadores autónomos, quienes realmente asumen finalmente los costes derivados de la obsolescencia de los estocages: componentes, instalaciones, maquinaria y formación de los trabajadores.

Por ejemplo, un indicador de la importancia del fenómeno de la subcontratación en la industria española es el peso de los consumos intermedios en la contabilidad de las empresas (porcentaje sobre el valor añadido bruto de las empresas que proviene de inputs externos intermedios), que en España se situaba a finales de este ciclo nada menos que en el $80 \%$ (Pérez Garíca et al. 2006). Así por ejemplo, la industria supone un $30 \%$ del destino de los servicios definidos como consumos intermedios. Aunque desde el punto de vista de la industria, en términos de valor añadido, los servicios suponen sólo un $11,8 \%$ de su estructura productiva, lo cual indica el relativo bajo valor añadido de este tipo de consumos.

Por otra parte, sabemos que el mayor protagonismo en el incremento del terciario lo han tenido precisamente los llamados servicios a las empresas, pues por ejemplo servicios tradicionales como el comercio y la reparación entre 1980 y 2002 vieron decrecer su peso en el empleo global del sector del 25,3\% al 21,6\%, la hostelería se mantuvo más o menos constante en torno al $6 \%$, y los servicios sociales y personales también decayeron dos puntos, del $43 \%$ al $41 \%$ mientras que la indefinida actividad "Otras actividades empresariales" pasó de un 7\% a un 13\% de peso en el empleo total y la de Servicios a las empresas se sitúa en el $10 \%$.

A continuación describimos cómo ha sido ese proceso en dos sectores paradigmáticos de la economía española desde que, en los años ochenta, llegara masivamente el capital transnacional, vía el aterrizaje de las grandes multinacionales, a los sectores industriales de fabricación de bienes intermedios y bienes de consumo masivo —orientados a la exportación-, y se iniciaran las grandes reformas laborales y la profunda reestructuración de nuestro sistema productivo ${ }^{15}$.

dirá así que son, por término medio, diez veces menos productivos que los primeros, aunque ello no significa que sean menos rentables para las empresas (OECD, Industry statistics, datos de 2005).

15 "Aumentan las entradas de capital extranjero en España", El País, 04/01/1981, esta noticia anunciaba el continuo incremento del flujo de capital extranjero en los años siguien- 


\subsection{Nuevos modelos de fabricación de bienes de consumo de gamas medias y bajas: el automóvil como paradigma}

La evolución de la industria del automóvil es sin duda alguna un campo excepcional para analizar estas transformaciones: el tipo de productos que se fabrican, las formas de organización del trabajo, la evolución de las condiciones de trabajo o la forma en que se desarrollan las relaciones laborales, entre otros factores. Pues no hay que olvidar que todavía a principios del siglo XXI para el continente europeo la industria del auto seguía siendo uno de los motores fundamentales del crecimiento económico, ocupando en torno a 2,2 millones de trabajadores en el conjunto de UE25 y representando en torno al $10 \%$ del valor añadido bruto por todo el conjunto de los sectores industriales (Carlsson-Aubry 2005).

En primer lugar, hay que destacar, como apuntábamos, que existen diferencias sustanciales entre los países del centro europeo, donde radican las sedes de las multinacionales constructoras, y la periferia, donde estas multinacionales instalan plantas de ensamblaje de modelos de gamas medias y bajas, como en España. Por tanto, a pesar de constatar un crecimiento continuado de la producción en los países semiperiféricos, las distancias en cuanto a productividad, composición de capital y valor añadido, se han venido ampliando respecto a los países centroeuropeos, en lo que podemos denominar como el desarrollo de un intercambio desigual en el que se producen continuas transferencias de valor del sur al norte en el intercambio de productos con distinta composición de capital: España exporta 2,5 millones de los 3 millones de vehículos (de gamas media y baja) que fabrica, mientras que de los 1,9 millones de vehículos que se consumen en España, el 65\% proceden de países del centro de Europa (gama alta) ${ }^{16}$.

tes a nuestro país. De tal manera que a finales de esa década, en 1998, el capital extranjero controlaba el $42 \%$ del valor añadido bruto de la industria, y suponía el $4 \%$ del PIB nacional anual. El principal sector de destino de la Inversión Extranjera Directa ha sido la Industria Manufacturera (39\% del total) -destacando la Fabricación de Productos Minerales no Metálicos, Metalurgia, Fabricación de Vehículos Motor e Industria Química - y la Información y las Telecomunicaciones (11,3\%). Según la Estadística de filiales de empresas extranjeras en España del año 2008 elaborada por el INE sabemos que el peso relativo de los trabajadores empleados en filiales extranjeras en el sector industrial alcanzaba el 15\% (en los servicios se reduce este porcentaje hasta el $9 \%$ ), y que se concentran en las empresas más grandes, pues las filiales extranjeras son una cuarta parte de todas las empresas que tienen entre 250 y 1000 empleados, y una tercera parte de las que tienen más de mil empleados. Lo cual indica que el capital extranjero se concentra en las empresas situadas en la cúspide de las cadenas de subcontratación, donde se realizan las tareas de más alto valor añadido. Pues, por ejemplo, el salario medio de los empleados para el conjunto de fíliales se situaba en 2008 nada menos que en 27.424 anuales y la tasa de valor añadido en el 31\%.

${ }^{16}$ Intervención de Joan Truyen, Secretario General de Industria, del Ministerio de Industria, Turismo y Comercio de España. Audiencia Pública del 26 de Abril de 2005 del Cars 21. 
Y lo que ocurre para los vehículos terminados pasa también para el intercambio intraeuropeo de componentes: mientras las piezas de más alto valor añadido, como los motores, las cajas de cambio o los sistemas de dirección, se siguen fabricando realmente en las sedes centrales de las multinacionales europeas, otros componentes de menos valor, que requieren más trabajo manual, como el cableado o el piecerío de plástico, se exportan de países como España al resto de Europa ${ }^{17}$.

Pues, además de instalarse plantas de fabricación cuya composición de capital es relativamente más intensiva en trabajo vivo, estas plantas, que basan su competitividad en los bajos costes laborales, han implementado los denominados sistemas de fabricación ligera y de producción justo a tiempo. El primero de ellos persigue, a su vez, externalizar al máximo las actividades de transformación o fabricación, para dejar en las plantas de montaje final las tareas esenciales de ensamblaje de componentes y subconjuntos de componentes, los cuáles se fabrican o subensamblan en la cadena de producción y subcontratación que constituye la industria auxiliar. Ello obviamente, permite trasladar las tareas allí donde los costes laborales son más baratos, bien por la menor capacidad de negociación de los trabajadores, bien porque se inscriben en otros convenios sectoriales (químicas, textil, servicios, etc.), o bien por que se van a lugares geográficos donde la normativa salarial y de condiciones de trabajo es más laxa. Pero también, mediante los sistemas de producción justo a tiempo, estas empresas consiguen trasladar los costes derivados de cualquier tipo de desajuste entre el comportamiento de la demanda y su oferta de vehículos a los escalones iniciales en la cadena de producción.

Los datos del Registro Mercantil reflejan prácticamente 1.500 empresas activas y autoclasificadas en el sector de fabricación de componentes para automoción (CNAE 343, 2511 y 3161 o IAE 3633), que emplearían en torno a 180.000 trabajadores. Sin embargo, sumando aquellas que, clasificándose en otros sectores, vinculan su actividad con la fabricación de piezas, repuestos o componentes para el

${ }^{17}$ Actualmente el sector de componentes en España exporta más del 50\% de su producción, exportación que se dirige fundamentalmente hacia la Unión Europea (cerca del 80\%); el valor de las importaciones, que se dirigen mayoritariamente a la industria constructora de vehículos, pero también en una proporción no desdeñable $(40 \%)$ a la propia industria de componentes, a pesar de distribuirse en muchos menos componentes, supera al de la exportación. Estos datos demuestran que el peligro de la deslocalización buscando bajos costes laborales se inicia siempre por los eslabones más alejados del producto final. Es decir, puede que las plantas de montaje final permanezcan en los países donde más coches se consumen, y puede que los principales proveedores sitúen cerca de ellas centros de subensamblaje y secuenciación, -tanto debido a que los costes de transporte son mayores para los vehículos terminados (ocupan más espacio) como al hecho de que el coste de transporte tiene una importancia menor a medida que se incrementa el valor añadido del producto- pero ello oculta un proceso real de continuos traslados de trabajos y productos a países con menores costes laborales. 
automóvil, el número de empresas asciende a más de 1900 e implica sumar 30.000 trabajadores más. Las aproximadamente 170 empresas de más de 250 trabajadores, acumulan el $76 \%$ del empleo total del sector de componentes, pero sólo las 50 empresas con mayor facturación concentran el $60 \%$ de la facturación total.

Al mismo tiempo, la producción de cada gama de vehículos se ve afectada por factores muy distintos de competitividad: en la fabricación de gamas bajas, las variaciones en los factores de producción, digamos estructurales, como el coste del transporte, las medidas medioambientales, las diferencias fiscales o los costes laborales inciden de forma más importante en el coste del producto final, y por tanto, en el riesgo de deslocalización. Por la propia estructura global del sector, las empresas de componentes son más intensivas en mano de obra. Por tanto, son más sensibles a las diferencias salariales con las economías en desarrollo. A medida que crecen los parques de proveedores en torno a las plantas de montaje de países de bajos salarios, los efectos de las diferencias globales en los costos de mano de obra se hacen más evidentes.

Este proceso de desarrollo del sector a nivel internacional, unido a la evolución del proceso de acumulación capitalista global, sitúa hoy a esos países que hemos identificado con la semiperiferia europea en una difícil encrucijada. Pues, en primer lugar, el mercado europeo de bienes de consumo masivo como el automóvil, debido a la paulatina disolución del estatuto salarial que venía asegurando ciertos niveles de demanda, se ha ido estancando poco a poco, en contraposición al fuerte incremento del consumo de automóviles en otros países emergentes como China ${ }^{18}$. Lo cual ha supuesto, por un lado, un intento de repatriación de empleo cualificado por parte de las grandes fabricantes hacia sus sedes centrales para incrementar la fabricación de coches de gamas altas y una progresiva deslocalización de plantas ensambladoras de gamas medias y bajas hacia esas economías.

De tal manera que, si bien al nivel de plantas fabricantes todavía no se ha observado una deslocalización masiva hacia países asiáticos (aunque sí a los países del este europeo desde hace varios años), el proceso de deslocalización ha empezado ya por los proveedores de componentes que se sitúan en los escalones de subcontratación más alejados del montaje final ${ }^{19}$. Aún así la necesidad de tomar posición en el

${ }^{18}$ El progreso de la capacidad productiva y de la capacidad de demanda de China es imparable, habiendo superado ya los ocho millones de vehículos con un ritmo de crecimiento anual en torno al $15 \%$.

${ }^{19}$ Por ejemplo, Delphi, una de las multinacionales fabricantes de componentes más importantes, cerraba la mayor parte de sus plantas europeas, despidiendo a más de 11.500 trabajadores en Estados Unidos y Europa, estaba abriendo otras plantas de bastante mayor capacidad productiva en países de más bajos costes laborales como Méjico o Marruecos. Por ejemplo, justo en el año 2.000 estaba construyendo una planta de cableado de 12.000 trabajadores en Tánger, mientras disponía ese año de nueve factorías en España, ubicadas en Pamplona, Logroño, Olvega (Soria), Tarazona (Zaragoza), Belchite (Zaragoza), Sant Boi de 
mercado chino ha multiplicado las "joint ventures" de constructores europeos, sumando en la última década el $60 \%$ del total de la inversión extranjera directa en la industria del automóvil china y alcanzando el $50 \%$ del total de la producción de vehículos en el país. De hecho, las predicciones de organizaciones internacionales del sector como Worldwide CSM, postulan un descenso muy significativo de la producción en España, mientras que los dos países centrales europeos consolidan y aumentan considerablemente su volumen de producción (Francia en un 9\% y Alemania en un $12 \%$ )

\subsection{El desarrollo del subdesarrollo en nuevas tecnologías de la información}

Hemos escogido también como campo de análisis el sector de las tecnologías de la Información y la Comunicación, porque, en primer lugar, viene siendo el protagonista, al menos desde la crisis estructural de los años 1970, de las promesas en torno al rejuvenecimiento del modelo de desarrollo del capitalismo. Y en segundo lugar, porque su papel estratégico en el crecimiento económico actual no sólo está vinculado a su peso directo en la riqueza como actividad industrial, sino también a todo el conjunto de efectos derivados en las actividades económicas intensivas en tecnología, así como - de forma todavía más determinante - a la evolución de las formas de organización del trabajo en el conjunto del sistema industrial. Dicho de otra manera, en el diseño de las tecnologías de la información (que implican determinadas formas de organizar su fabricación; determinados perfiles de operarios; determinadas condiciones de trabajo, etc), están ya inoculados, en gran medida, el tipo de productos -y las formas de fabricarlos- que se pueden elaborar con ellas.

Dentro del sector de las TICs encontramos, sin embargo, diferencias entre distintas áreas de actividad en cuanto a su función en el sistema productivo. En primer lugar, podemos distinguir la producción de información (servicios software, diseño de sistemas, soluciones, etc.) de la fabricación de los soportes que gestionan la información (el espacio propio de las telecomunicaciones). Dentro de este último área, podemos diferenciar, a su vez, la instalación y mantenimiento de las redes de telecomunicaciones y la fabricación manufacturera de los componentes electrónicos.

Las pautas de localización en los últimos años en cuanto a estas distintas actividades en el caso Español ha sido: la casi total deslocalización de las manufacturas a

Llobregat (Barcelona), Sant Cugat del Vallés (Barcelona) y dos en Cádiz, con una plantilla global de 7.000 trabajadores. El centro tecnológico (ingeniería y dirección), hasta el año 2.000, estaba en la planta de Landaben, con una plantilla, en ese año, de 200 personas y una facturación anual que superaba los ochocientos millones de pesetas. ("Delphi Unicables de Pamplona no espera cambios tras desgajarse su división de la empresa General Motors", noticia del Diario de Navarra de 30 de marzo de 1999, p.77.), sin embargo al año siguiente, en 2001, comenzó a cerrar estas plantas, empezando por Ólvega, siguiendo por la de Tarazona en 2004, y terminando por el tristemente famoso cierre de sus factorías en Cádiz, en 2007, justo el año que abría una planta de 1.000 empleados en Rumanía. 
países de bajos costes fuera de la $\mathrm{OCDE}^{20}$; el fortalecimiento del área de telecomunicaciones pero a costa de una fuerte oligopolización del mercado nacional por parte de grandes multinacionales que subcontratan parte de las actividades a medianas y pequeñas empresas en cada territorio ${ }^{21}$.

El área que denominábamos de producción de software, que administrativamente se incluye en «Programación y Consultoría Informática», ha sido la que más se ha desarrollado en España en los últimos años en términos de volumen de negocio y de creación de empleo. En particular, las llamadas factorías de software han soportado una gran parte del peso de dicho desarrollo. Pues el intenso incremento del sector de fabricación del software en las últimas décadas ha supuesto un continuo proceso de racionalización de los procesos de producción, en el que las citadas factorías son un elemento central.

En primer lugar, la racionalización de los procesos productivos arranca ya de los sectores industriales a los cuáles estas empresas ofrecen servicios de offshoring. Por eso, en el caso de la industria del software es realmente difícil hablar de un sector en sí mismo, dado que sus productos estrella son "soluciones" para otros sectores y la automatización funcional de actividades y saberes-hacer que forman parte importante de procesos productivos de áreas muy diversas (banca, sanidad, seguros, administración pública, contabilidad empresarial, industria, etc.), siendo cada vez menos exacto hablar de un "sector de las telecomunicaciones" como una única realidad. Pues la dispersión de actividades de un mismo proceso productivo en sectores productivos diversos, hace que el análisis sectorial incluya a muchas empresas y trabajadores que están, pero no son, y que obvie a otros que son pero no están.

Al principio, la llamada fabricación de "soluciones" informáticas implicaba un trabajo de análisis, diseño y programación casi artesanal, realizado por equipos de ingenieros informáticos altamente cualificados en un mercado poco competitivo en medianas empresas del sector denominadas "Consultoras", pero poco a poco la

${ }^{20}$ El fenómeno de la deslocalización de las empresas de fabricación de productos TIC hacia el sureste asiático y los nuevos países de la ampliación europea, ha sido generalizado en los últimos diez años en toda Europa, incluido nuestro país. Por ejemplo, la Unión Europea, EE.UU. y Japón acogían en 1990 el 80\% de la producción de bienes TIC, y en poco más de diez años ese porcentaje se ha reducido hasta un $8 \%$, trasladándose la producción a China y otros países asiáticos. The IPTS Report - versión española- n 77 (septiembre/2003), "Número especial: La sociedad de la información y la ampliación de la Unión Europea" editado por el Instituto de Prospectiva Tecnológica y el Observatorio Europeo de Ciencia y Tecnología en www.jrc.es (11-1-2006).

${ }^{21}$ Las únicas tareas manuales en el ámbito del hardware que todavía quedan en los países occidentales como el nuestro son las tareas relacionadas con la instalación de redes, centrales y sistemas, pero estas tareas no son realizadas por las grandes compañías proveedoras de servicios, sino que son subcontratadas a otras empresas. 
demanda de proyectos fue incrementándose, la competencia entre empresas y el ajuste de precios fue creciendo... y se dio paso a la división del trabajo como estrategia de racionalización, quedando cada vez más definida la separación del trabajo manual y el trabajo mental. El primero lo realizan los programadores o desarrolladores, y el segundo los analistas y arquitectos funcionales. Ello permitía a las fabricantes de soluciones ampliar la producción manteniendo un grupo relativamente reducido de trabajadores altamente cualificados y un grupo cada vez más amplio de programadores, con salarios menores, a los que se exigía una relativa menor cualificación (Castillo 2007).

A partir de esta división, se procedió a la progresiva subcontratación de las tareas de programación (la escritura del código). Con ello las empresas se dotaban de la flexibilidad necesaria para hacer frente a la relativa dificultad para prever la duración y la cantidad de recursos humanos necesarios para cada proyecto. No obstante ello fue posible gracias a una nueva forma de diseñar las soluciones informáticas, mediante una concepción modular, que, al igual por ejemplo, que en el caso de los automóviles, permitiera fabricar productos específicos para cada cliente a partir del diferente ensamblaje final de módulos estándares entre sí en origen.

Las denominadas Factorías del Software son empresas de tamaño mediano localizadas en regiones españolas de relativos bajos costes laborales (Badajoz, Cáceres, Albacete, Salamanca, Oviedo, etc.) que contratan a informáticos jóvenes para realizar esas tareas de escritura de código. Así, en las empresas cabeza -en el front office- hay sólo un reducido grupo de personal muy cualificado: los jefes de proyecto se encargan de la relación con el cliente y los llamados arquitectos diseñan la arquitectura del proyecto, dividen su fabricación en paquetes, y los envían a las factorías del software, mientras que, al interior de las factorías, en el back office, hay varias categorías: los "Gestores" de la factoría reciben los paquetes, calculan el coste y el tiempo que les puede suponer (mil horas, mil quinientas horas, etc.) y hacen un presupuesto, si consiguen el contrato, distribuyen el trabajo "encapsulándolo" de nuevo, con ayuda de un técnico senior (analista funcional), a los jefes de proyecto que dirigen los equipos de "constructores" (o desarrolladores), Unidades de Trabajo [UT]. Los equipos, que fabrican cada una de esas cápsulas, suelen componerse de seis personas, dos constructores seniors y cuatro juniors.

Para hacer viable este sistema de trabajo que permite tanto la externalización de tareas y la fácil sustitución de los empleados que escriben el código, se utilizan protocolos de certificación como el llamado CMMI (Capability Maturity Model Integration, «Modelo de madurez de la capacidad») $)^{22}$. Estos protocolos permiten la

${ }^{22}$ Tal y como lo presentaba una compañía de consultoría y servicios de tecnologías de la información, en pleno proceso de implementación del CMMI en su departamento de desarrollo, la automatización de las funciones posibilitada por el nuevo estándar de calidad capacitaría a la organización para: realizar estimaciones realistas; hacer estudios de viabilidad; evaluar propuestas de proveedores; analizar alternativas de distintos calendarios y 
estandarización de los procesos de trabajo, pues implican seguir siempre el mismo patrón en los modos de hacer las soluciones y de resolver problemas, lo cual reduce las exigencias de conocimiento y habilidad a términos medios, y compensa esta pérdida cualitativa estableciendo dispositivos tendentes a la intensificación del trabajo o la rotación de los trabajadores, con salarios medios en torno a los mil euros mensuales.

De esta forma, el caso las fábricas de software y los sistemas de certificación de la calidad de los procesos han introducido modelos de gestión de las relaciones laborales heredados del Toyotismo: la mejora continua, la autoactivación, la reingeniería de procesos, el cambio continuo, etc. Esto es, hacerlo cada vez más rápido y a menor coste. Lo cual va a suponer, en general, una baja calidad relativa en los servicios ofertados al cliente final por parte de las empresas que demandan estas soluciones y una fuerte limitación a las posibilidades de desarrollo hacia el futuro del sector.

En definitiva, todos estos factores han hecho que en el caso de las tecnologías de la información también se haya producido una suerte de estratificación a nivel Europeo entre el centro y la periferia marcado por el tipo de desarrollo que denominábamos de intercambio desigual: en el que, a pesar de que todos los países ven incrementado el peso del sector de las nuevas tecnologías de la información en sus economías, las diferencias que separan los ritmos de crecimiento del sector y el grado de innovación entre unos y otros se han ido ampliando ${ }^{23}$.

$\mathrm{Y}$ todo ello va a suponer, en primer lugar, un intenso incremento de la dependencia tecnológica respecto de los países de Europa central. Por ejemplo, en el sector de bienes de equipo en España la cuota teórica del mercado interno cubierta por la producción propia se situará, después de este proceso sólo en un $22,3 \%$, muy alejada de tasas de cobertura media del $45 \%$ en el conjunto de la UE. Además de ello, se observa un grado de especialización deficiente, que impide cubrir la deman-

tamaños de equipo; acabar con las falsas expectativas de calendarios imposibles; predecir la calidad de un producto; dimensionar los equipos de mantenimiento o de garantías; evaluar objetivamente el progreso de un proyecto; elaborar informes detallados de progreso; gestionar con cuadros de mando por proyecto; anticiparse a las desviaciones; analizar alternativas para corregir las desviaciones; reconocer cuantitativamente las mejoras del proceso; justificar el retorno de las inversiones en mejora; realizar benchmarking del proceso software (www.ati.es/IMG/pdf/GESEIN2007.pdf).

${ }^{23}$ Según datos de la OCDE, si en España este porcentaje, en el año 1995 alcanzaba el $5 \%$ del PIB, diez caños después había aumentado sólo hasta el $6 \%$, mientras que la media de la Europa de los 15 había pasado del 7\% al 12\% en esos años. Así, en el ranking europeo de empresas según su volumen de gasto en I+D España tan sólo cuenta con la presencia de Teléfonica e INDRA entre las 150 principales empresas europeas (en los puestos 41 y 116 respectivamente según el último informe de 2008. Joint Research Center, The 2008 EU Industrial R\&D Investment SCOREBOARD, Comisión Europea, Octubre 2008. 
da nacional en bienes de intensidad tecnológica alta o media alta con producción propia. Pues el mayor peso en el ámbito español en dicho sector lo ocupan actividades de mantenimiento y montaje sin base sólida en actividades de fabricación y de investigación propia, lo que determina, por último, una realidad productiva vulnerable al proceso de internacionalización que caracteriza al sector.

Así, este déficit tecnológico de la economía española se va a plasmar en algunos indicadores significativos: la balanza de pagos tecnológica, que recoge la relación entre ingresos y pagos en concepto de royalties (pagos por patentes) no sólo es preocupantemente negativa, sino que se ha incrementado notablemente en las últimas décadas, pues ha pasado del $8 \%$ en 1985 al $40 \%$ en la actualidad. Ello concuerda con los datos de la evolución de una balanza de pagos de bienes de equipo bastante negativa, pues como media, el valor de las importaciones ha duplicado al de las exportaciones en las dos últimas décadas en el sector, es decir, con tasas de cobertura del 54\% según los informes de la patronal (SERCOBE 2010)

\section{Conclusiones}

El recurso al capital financiero desde que hace tres décadas se evidenciaran los primeros indicios del agotamiento del Modelo Fordista-Keynesiano en Occidente, permitió aplicar formas de extracción de plusvalor centradas en la sobreexplotación del trabajo, o la esquilmación de los recursos técnicos y humanos disponibles, embargando las posibilidades de desarrollo de países como España a medio y largo plazo, mientras, al mismo tiempo, se procedía a la transferencia del capital productivo hacia nuevas economías emergentes con bajos costes laborales.

Sin embargo, en la inversión «fetichista» del proceso conflictivo real que ha conducido a la concentración del poder en el capital financiero, la crisis financiera actual se ha presentado como la coartada legitimatoria de las nuevas medidas de ajuste a tomar tanto en el ámbito productivo (estrategias de rentabilidad empresarial), como en el laboral (regulación del estatuto salarial). Factores que inciden en el cambio hacia un modelo de desarrollo basado en la intensificación del trabajo como principal factor de rentabilidad y competitividad y en el predominio de un modelo de gobierno corporativo en las empresas dirigido por el capital financiero ${ }^{24}$.

\footnotetext{
${ }^{24}$ Así, por ejemplo, y en términos generales, la productividad media en España ha decrecido respecto a la Unión Europea y respecto a la misma tasa hace veinte años, a pesar de haber seguido una tasa relativamente mayor de crecimiento económico que la media del resto de países europeos. Sin ir más lejos distintos informes del Banco de España coinciden abiertamente con este análisis: "El alto ritmo de creación de empleo que ha tenido lugar en estas actividades de servicios se ha conjugado con un avance muy moderado de su productividad, que durante el período analizado ha sido sistemáticamente inferior al registrado en la industria" (Gordo, Jareño y Urtasun, 2006: 13). En síntesis, y glosando el informe del
} 
El sistema productivo español ha ocupado un lugar específico, semiperiférico, en esas dinámicas económicas y productivas globales, caracterizadas por la concentración de capitales a nivel mundial; la fragmentación de los procesos productivos y su dispersión geográfica mediante la externalización, subcontratación y deslocalización de las fases de menos valor añadido hacia zonas cada vez más alejadas de la venta del producto final ${ }^{25}$.

De tal manera que el llamado milagro económico español de los últimos treinta años no ha consistido sino en el consumo adelantado de los recursos económicos, técnicos y humanos de nuestro futuro a medio plazo, pues se ha basado, por una parte, en el sostenimiento de los niveles de consumo y de inversión mediante capital financiero y, por otra, en la intensificación del trabajo por encima de las propias necesidades de reproducción de la fuerza de trabajo. Lo que ha ido minando también, al mismo tiempo, la capacidad de resistencia de los trabajadores vía la propia desvalorización de la fuerza de trabajo y la individualización de las relaciones laborales.

Conference Board Europe, "España es el país de la UE en el que más ha caído la productividad en los últimos quince años". En los primeros años del nuevo siglo fue el único país, junto con Italia que registró un empeoramiento de la productividad, cuando descendió un $1,3 \%$, cayendo a una tasa interanual del $0,6 \%$, mientras que la media europea crecía a un 1,7\%. El Pais, 9/3/2006, p. 34.

${ }^{25}$ Desde mediados de la primera década del siglo XXI se producirá una progresiva desinversión del capital extranjero mediante la deslocalización de fragmentos de la producción a nuevos países emergentes. Observándose, desde el inicio de la crisis económica de 2008, cuando España llegaba a ser el sexto país a nivel mundial que más Inversión Extranjera Directa (IED) recibía, un retroceso de un $60 \%$ en estos flujos de inversión. Además gran parte de las nuevas inversiones extranjeras está destinada a financiar desinversiones: pues se calcula que la mitad de los flujos que llegaban en la última década son expedidos a otros países a través de las entidades tenedoras de valores en el extranjero (ETVE). Lo cual se unirá a la progresiva deslocalización de capital de algunas grandes empresas españolas. Por ello el flujo neto comenzará a ser negativo a partir del año 2003 (Ministerio de Industria Turismo y comercio, 2010). 


\section{Referencias bibliográficas}

Aglietta, M. (2008), "Corporate governance and the long-run investor", International Review of Applied Economics, 22(4), pp. 407-427. (2002), El FMI. Del orden monetario a los desórdenes financieros, Madrid, Akal, 2002.

Aglietta, M. y Breton, R. (2001), "Financial systems, corporate control and capital accumulation", Economy and Society, 30(4), pp. 433-466.

Aglietta, M., Khanniche, S. y Rigot, S. (2010), Les hedge funds. Entrepreneurs ou requins de la finance?, Paris, Perrin.

Álvarez, I. y Medialdea, B. (2010), "La influencia de la financiarización sobre el gobierno corporativo de la empres a: el papel de los inversores institucionales", Revista de Economía Mundial, 24, pp. 165-191.

Álvarez, I. y Luengo, F. (2010), "Financiarización, empleo y salario en la UE: el impacto de las nuevas estrategias empresariales", WP04/10, Instituto Complutense de Estudios Internacionales, Universidad Complutense de Madrid.

Boyer, R. (2011), Les financiers détruiront-ils le capitalisme?, Paris, Economica. (2008), “A finance-led growth regime?”, en Ismail Eturk et al., Financialization at work, London, Routledge, pp. 175-190.

Boyer, R. (2000), "The Political in the Era of Globalization and Finance: Focus on Some Régulation School Research", International Journal of Urban and Regional Research, 24(2), pp. 274-322.

Brenner, R. (2009), La economía de la turbulencia global, Madrid, Akal.

Carlsson-Aubry, C. (2005), "The motor vehicle industry in the European Union", Statistics in focus, 4/2005, EUROSTAT.

Cartron, D., y Gollac, M. (2003), "Intensité et conditions de Travail", Quatre Pages 58, Centre d'Etudes de l'Emploi.

Castel, R. (1997), Las metamorfosis de la cuestión social, Buenos Aires, Paidós.

Castillo, J. J. (1998), A la búsqueda del trabajo perdido, Editorial Tecnos, Madrid. (2007), El trabajo fluido en la sociedad de la información: organización y división del trabajo en las fábricas de software, Buenos Aires, Miño y Dávila.

Crotty, J. (2005), “The Neoliberal Paradox: The Impact of Destructive Product Market Competition and 'Modern' Financial Markets on Nonfinancial Corpora- 
tion Performance in the Neoliberal Era", en G. A. Epstein (ed.), Financialization and the World Economy, Cheltenham, Reino Unido, pp. 77-110.

Davis, E. P. y Steil, B. (2001), Institutional Investors, Cambridge, MIT Press.

Echeverría, S., Carpintero Redondo, O. y Naredo Pérez, J. M. (1999), "Riqueza real y riqueza financiera: el papel de los flujos financieros en la generación y distribución de la capacidad de compra sobre el mundo", en Valero, A. y Naredo, J. M. (coords.), Desarrollo económico y deterioro ecológico, Madrid, Visor / Fundación Argentaria, pp. 349-382.

Epstein, G. A. y Jayadev, A. (2005), "The Rise of Rentier Incomes in OECD Countries: Financialization, Central Bank Policy and Labor Solidarity", en G. A. Epstein (ed.), Financialization and the World Economy, Cheltenham, Reino Unido, pp. 46-74.

Fondo Monetario Internacional (2007), Perspectivas de la economía mundial. Desbordamientos y ciclos de la economía mundial (disponible en www.imf.org/external/pubs/ft/weo/2007/01/esl/sums.pdf).

Froud, Julie et al.(2006), Financialization and strategy. Narrative and Numbers, London, Routledge.

Geed, R.(2009), "The rise of internal capitalist diversity? Changing patterns of finance and corporate governance in Europe", Economy and Society, 38(4), pp. 552-579.

Gordo, E., Jareño, J. y Urtasun, A. (2006), Radiografia del sector de servicios en España, Documentos Ocasionales, $n^{\circ}$ 0607, Banco de España.

Gourevitch, Peter A. y Shinn, James (2005), Political Power \& Corporate Control. The new global politics of corporate governance, Princeton University Press.

King, William R. (2006), "Offshoring decision time is at hand", Information Systems Management, 23 (3), Summer.

Krippner, G. (2011), Capitalizing on Crisis: The Political Origins of the Rise of Finance, Harvard University Press. (2005), "The financialization of the American economy", Socio-Economic Rreview, 3, pp. 173-208.

Lazonick, W. y O’Sullivan (2000), "Maximazing shareholder value: a new ideology for corporate governance", Economy and Society, 29(1), pp. 13-35.

López, I. y Rodríguez, E. [Observatorio Metropolitano] (2010), Fin de ciclo. Financiarización, territorio y sociedad de propietarios en la onda larga del capitalismo hispano (1959-2010), Madrid, Traficantes de Sueños. 
Marx, Karl (1867-1894): El Capital, Fondo de Cultura Económica, México.2ª ed. 1959,

Ministerio de Industria Turismo y comercio (2010), La inversión extranjera directa en España, Informe 2010, Madrid.

Mouhoud, El M. y Plihon, D. (2009), Le savoir \& la finance. Liaisons dangereuses au coeur du capitalisme contemporain, Paris, La Découverte.

Naredo, J. M. (1998), La burbuja inmobiliario-financiera en la coyuntura económica reciente (1985-1995), Madrid, Siglo XXI.

Naredo, J. M., Carpintero, O. y Marcos, C. (2007), "Boom inmobiliario, ahorro y patrimonio de los hogares evolución reciente y comparación internacional", Cuadernos de Información Económica, 200, pp. 71-91.

Orhangazi, O. (2008a), "Wall Street vs. the Labor Movement" New Labor Forum, 17(1): 101-107. (2008b), "Financialization and capital accumulation in the nonfinancial corporate sector: A theoretical and empirical investigation of the US economy, 1973-2004", Cambridge Journal of Economics, 32, pp. 863-886. (2007). Financialization and the US economy, Northampton, MA, Edward Elgar.

Palloix, Christian: Proceso de producción y crisis del capitalismo. H. Blume Ediciones, Madrid, 1980, 222.

Pérez García, F. et al. (2006), Productividad e internacionalización. El crecimiento español ante los nuevos cambios estructurales. Bilbao, Fundación BBVA.

Plihon, D. (2009), Le nouveau capitalisme, Paris, La Découverte.

Plihon, D : y Mouhoud, El M. (2009), Le savoir et la finance. Liaisons dangereuses au coeur du capitalisme contemporain. Paris, La Decouverte.

Ricardo, D. (1994), Principios de Economía Política y Tributación, [ed. orig. 1817], Fondo de Cultura Económica, México.

SERCOBE / Asociación Española de Fabricantes de Bienes de Equipo (2010), La industria española de bienes de equipo 2010.

Zalewski, D. A. y Whalen, Ch. J. (2010), "Financialization and Income Inequality: A Post Keynesian Institutionalist Analysis", Journal of Economic Issues, XLIV(3), pp. 757-777. 